\title{
Efficacy and safety of moxifloxacin in acute exacerbations of chronic bronchitis: a prospective, multicenter, observational study (AVANTI)
}

\author{
Alexander Chuchalin ${ }^{1}$, Maryna Zakharova ${ }^{2}$, Dejan Dokic ${ }^{3}$, Mahir Tokić ${ }^{4}$, Hans-Peter Marschall ${ }^{5}$ and Thomas Petri ${ }^{6^{*}}$
}

\begin{abstract}
Background: Acute exacerbations of chronic bronchitis (AECB), including chronic obstructive pulmonary disease (AECOPD), represent a substantial patient burden. Few data exist on outpatient antibiotic management for AECB/ AECOPD in Eastern/South Eastern Europe, in particular on the use of moxifloxacin (Avelox ${ }^{\circledR}$ ), although moxifloxacin is widely approved in this region based on evidence from international clinical studies.

Methods: AVANTI (AVelox ${ }^{\circledR}$ in Acute Exacerbations of chroNic bronchiTls) was a prospective, observational study conducted in eight Eastern European countries in patients $>35$ years with AECB/AECOPD to whom moxifloxacin was prescribed. In addition to safety and efficacy outcomes, data on risk factors and the impact of exacerbation on daily life were collected.

Results: In the efficacy population ( $N=2536)$, chronic bronchitis had been prevalent for $>10$ years in $31.4 \%$ of patients and $66.0 \%$ of patients had concomitant COPD. Almost half the patients had never smoked, in contrast to data from Western Europe and the USA, where only one-quarter of COPD patients are non-smokers. The mean number of exacerbations in the last 12 months was 2.7 and $26.3 \%$ of patients had been hospitalized at least once for exacerbation. Physician compliance with the recommended moxifloxacin dose (400 mg once daily) was 99.6\%. The mean duration of moxifloxacin therapy for the current exacerbation (Anthonisen type I or II in 83.1\%; predominantly type I) was $6.4 \pm 1.9$ days. Symptom improvement was reported after a mean of $3.4 \pm 1.4$ days. After 5 days, $93.2 \%$ of patients reported improvement and, in total, $93.5 \%$ of patients were symptom-free after 10 days. In the safety population ( $\mathrm{N}=2672), 57$ (2.3\%) patients had treatment-emergent adverse events (TEAEs) and 4 (0.15\%) had serious TEAEs; no deaths occurred. These results are in line with the known safety profile of moxifloxacin.

Conclusions: A significant number of patients in this observational study had risk factors for poor outcome, justifying use of moxifloxacin. The safety profile of moxifloxacin and its value as an antibiotic treatment were confirmed. Physicians complied with the recommended $400 \mathrm{mg}$ once-daily dose in a large proportion of patients, confirming the advantages of this simple dosing regimen.
\end{abstract}

Trial registration: ClinicalTrials.gov identifier: NCT00846911

Keywords: Antibiotics, Chronic bronchitis, COPD, Exacerbations, Moxifloxacin

\footnotetext{
* Correspondence: thomas.petri@bayer.com

${ }^{6}$ Bayer Pharma AG, Berlin 13353, Germany

Full list of author information is available at the end of the article
} 


\section{Background}

Acute exacerbations of chronic bronchitis (AECB), including chronic obstructive pulmonary disease (AECOPD), represent a substantial disease burden to patients, contributing to reduced lung function, increased morbidity and mortality, and long-term impairment in quality of life [1-8].

A role for bacteria is implicated in $40-50 \%$ of AECB episodes [9]. In a routine clinical setting, where bacteriological assessment may not be available, empirical antibacterial therapy is generally recommended for patients who fulfill specific clinical criteria, with the aim to influence the disease course and prevent complications [10-12]. Guidelines by Woodhead et al. [12] recommend antibiotic therapy for patients with increased dyspnea, sputum volume, and sputum purulence (Anthonisen type I) and for patients with two of these symptoms including increased sputum purulence (Anthonisen type II), but not in patients with one of these symptoms alone (Anthonisen type III) [13]. The GOLD recommendations for antibiotic therapy are based on the severity of exacerbations, the presence of risk factors, and predictors of poor outcome (e.g. comorbid conditions, frequency of AECBs, and previous antibiotic use) [10]. Using these criteria, the GOLD guidelines recommend amoxicillin/clavulanate or fluoroquinolones in patients with moderate to severe exacerbations.

Moxifloxacin is a fourth-generation fluoroquinolone with a broad spectrum of activity relevant to the microorganisms isolated in AECB, including Gram-positive and Gram-negative bacteria, atypical pathogens, and anaerobic bacteria, as well as species resistant to aminoglycosides, tetracyclines, and macrolide antibiotics. Beta-lactamase producing strains of Haemophilus influenzae and Moraxella catarrhalis are susceptible to moxifloxacin [14-17]. Moxifloxacin is strongly targeted to alveolar tissue $[18,19]$ and demonstrates rapid initial killing and eradication rates for pneumococcal bacteria [16].

The initial clinical program for moxifloxacin in AECB included two studies of moxifloxacin (400 $\mathrm{mg}$ once daily, 5 days) versus clarithromycin (500 $\mathrm{mg}$ twice daily, 7-10 days) and two studies versus cefuroxime axetil (500 mg twice daily, 10 days) in a total of 2381 patients $[20,21]$. Together, these studies demonstrated that moxifloxacin achieved a clinical response rate of $89 \%$ and a bacteriological response rate of $87 \%$ at $7-14$ days post-treatment.

In another, prospective, multicenter, randomized, doubleblind study of outpatients with AECB (MOSAIC), 5-day moxifloxacin was associated with significantly higher clinical cure rates and bacterial eradication rates than a 7-day standard regimen (i.e. amoxicillin $500 \mathrm{mg}$ three times daily, or clarithromycin $500 \mathrm{mg}$ twice daily, or cefuroxime axetil $250 \mathrm{mg}$ twice daily) [22]. In addition, the time until next exacerbation was significantly greater with moxifloxacin than the comparator during 9-month follow-up [22], which may be attributed to more effective bacterial eradication by moxifloxacin [23]. Post-hoc analyses of the MOSAIC study identified a beneficial influence on clinical cure rates from moxifloxacin treatment and a poorer outcome associated with cardiopulmonary disease, forced expiratory volume in 1 second $\left(\mathrm{FEV}_{1}\right)$ $<50 \%$ predicted, and $\geq 4$ AECBs in the previous year [24].

The recent MAESTRAL study of 1492 outpatients aged $\geq 60$ years with moderate-to-severe AECOPD (Anthonisen grade I) showed that moxifloxacin (400 mg/day for 5 days) is as effective as amoxicillin/clavulanic acid (875/ $125 \mathrm{mg}$ for 7 days) in clinical success rate, with a significantly lower failure rate in patients with confirmed bacterial AECOPD [25]. The benefits of moxifloxacin (400 mg/day for 5 days) also translated into a more favorable long-term quality of life when compared with amoxicillin/clavulanate $(500 / 125 \mathrm{mg}$ three times daily for 10 days) in the general practice setting [26].

Based on the existing controlled trial evidence, researchers have concluded that moxifloxacin is as effective or even more effective compared with other antimicrobials, with a more advantageous dosage regimen that may be associated with increased compliance [27,28].

Observational studies provide valuable information, alongside controlled clinical studies, with relevance to contemporary practice. Published data on 9225 patients aged $\geq 35$ years with AECB or AECOPD from eight European countries, from among the 46893 patients recruited globally to an observational study of moxifloxacin (the GIANT study), demonstrated very good or good efficacy for moxifloxacin in $94.9 \%$ of patients and very good or good tolerability in $96.7 \%$, based on physician assessments [29].

Few data exist on the outpatient antibiotic management of AECB/AECOPD in Eastern/South Eastern Europe, and in particular on the use of moxifloxacin in this population. The current non-interventional observational study was conducted to gain further information on the treatment of AECB with moxifloxacin in a large population of outpatients with moderate-to-severe AECB recruited from countries in South Eastern/Eastern Europe and Kazakhstan.

\section{Methods}

\section{Study design}

The AVANTI study (AVelox ${ }^{\circledR}$ in Acute Exacerbations of chroNic bronchiTIs) was a prospective, multicenter, observational study conducted at 182 investigational centers in 8 countries (Albania, Bosnia and Herzegovina, Kazakhstan, Macedonia, Moldova, Russian Federation, Slovakia, and Ukraine) between 8 April 2008 and 6 April 2010.

The observational period for each patient commenced at the initiation of treatment with moxifloxacin $\left(\right.$ Avelox $\left.^{\circledR}\right)$ 
for AECB and was continued until an improvement or relief of symptoms at follow-up visit or premature discontinuation. Up to two follow-up visits were planned, with the last assessment following the final intake of moxifloxacin.

\section{Patients}

Male or female outpatients aged $\geq 35$ years with a diagnosis of AECB were included in the study. The diagnosis of AECB and of any concomitant diseases was provided by attending physicians, who were pulmonologists or internal medicine specialists (approximately 60\%), general practitioners (10\%), or practitioners from other specialties. An exacerbation of chronic bronchitis was considered to be present when the patient experienced an acute increase in respiratory symptoms, including dyspnea, sputum volume, and/or sputum clearance. Exacerbations were classified into Anthonisen types I, II, or III [13]. Exclusion criteria were limited to contraindications to the use of moxifloxacin, as described in the locally available Summary of Product Characteristics.

Data on disease characteristics, risk factors, and the impact of exacerbations on daily life were collected from patients before initiation of moxifloxacin treatment.

The study protocol was approved by the local independent ethics committee or institutional review board, as applicable, at each of the investigator sites. At the national level, the study was approved in Albania by the Bioethics National Committee of the Ministry of Health, in Moldova by the National Ethical Committee, in the Russian Republic by the Ethical Committee at the Federal Service on Surveillance in Healthcare and Social Development, in Slovakia by the Ethical Committee of the Bratislava Region, and in Ukraine by the Central Ethics Commission of the Ministry of Health. Notification on the study protocol, following regulatory requirements for non-interventional studies, was provided in Bosnia and Herzegovina to the Ministry of Health, and in Kazakhstan to the local regulatory authority and the National Center for Drug Expertise, Medical Devices and Medical Equipment. In Macedonia, no ethics committee approval or notification was requested at national level. All patients provided informed consent in accordance with local regulations.

\section{Study medication}

Moxifloxacin was prescribed according to the medical judgment of the investigator and in accordance with the guidelines from the European Medicines Agency, the US Food and Drug Administration, and local regulations (e.g. Avelox $^{\circledR}$ (moxifloxacin hydrochloride) US prescribing information [30]).

The dose of moxifloxacin recommended for the treatment of AECB in the study was $400 \mathrm{mg}$ once daily, consistent with the local Summary of Product Characteristics. Final decisions on the dose of moxifloxacin and on the use of concomitant medications were at the discretion of the attending physician.

\section{Efficacy and safety assessments}

Efficacy assessments for each patient included the frequency of improvement of different symptoms (including sputum volume, sputum character, fever, cough, and dyspnea), the frequency of cure (i.e. symptom-free status), the time to improvement in symptoms and to cure, and general assessments of the effectiveness of moxifloxacin treatment using methodologies similar to those employed in the GIANT study [29].

Safety evaluations included adverse events reported during the study, coded using the Medical Dictionary for Regulatory Activities (MedDRA) version 13.0, and a general subjective tolerability assessment by investigators.

Physicians additionally provided summary assessments of the overall efficacy and tolerability of moxifloxacin into the categories: 'very good', 'good', 'sufficient', and 'insufficient'. Both physicians and patients provided an assessment of their satisfaction with the therapeutic effect of moxifloxacin. Finally, for patients with available data, physicians compared the overall effect and onset of action of moxifloxacin against the antibiotic used to treat the previous episode of AECB.

\section{Statistical analyses}

Efficacy and safety outcomes were analyzed by descriptive statistics. As appropriate for non-interventional studies, statistical tests were not performed. The safety population included all patients who took at least one dose of study medication and provided information on adverse events. The efficacy population included all patients who took at least one dose of study medication and provided information on the efficacy of treatment.

A minimum of 1600 patients were planned to be included in the study. As 2672 patients were actually included, adverse events occurring at a frequency of $0.125 \%$ (1:800 patients) could be detected with a probability of $95 \%$.

\section{Results}

\section{Patient population}

A total of 2672 patients were enrolled in the study and included in the safety population. The efficacy population consisted of 2536 patients, after exclusion of 136 (5.1\%) patients from the safety population, most commonly because of age $<35$ years $(n=119)$ (Figure 1$)$.

Demographic and disease characteristics of the efficacy population at baseline are presented in Table 1. Patient ages ranged from 35 to 94 years, with approximately one-third of patients (31.6\%) aged above 65 years. Over 


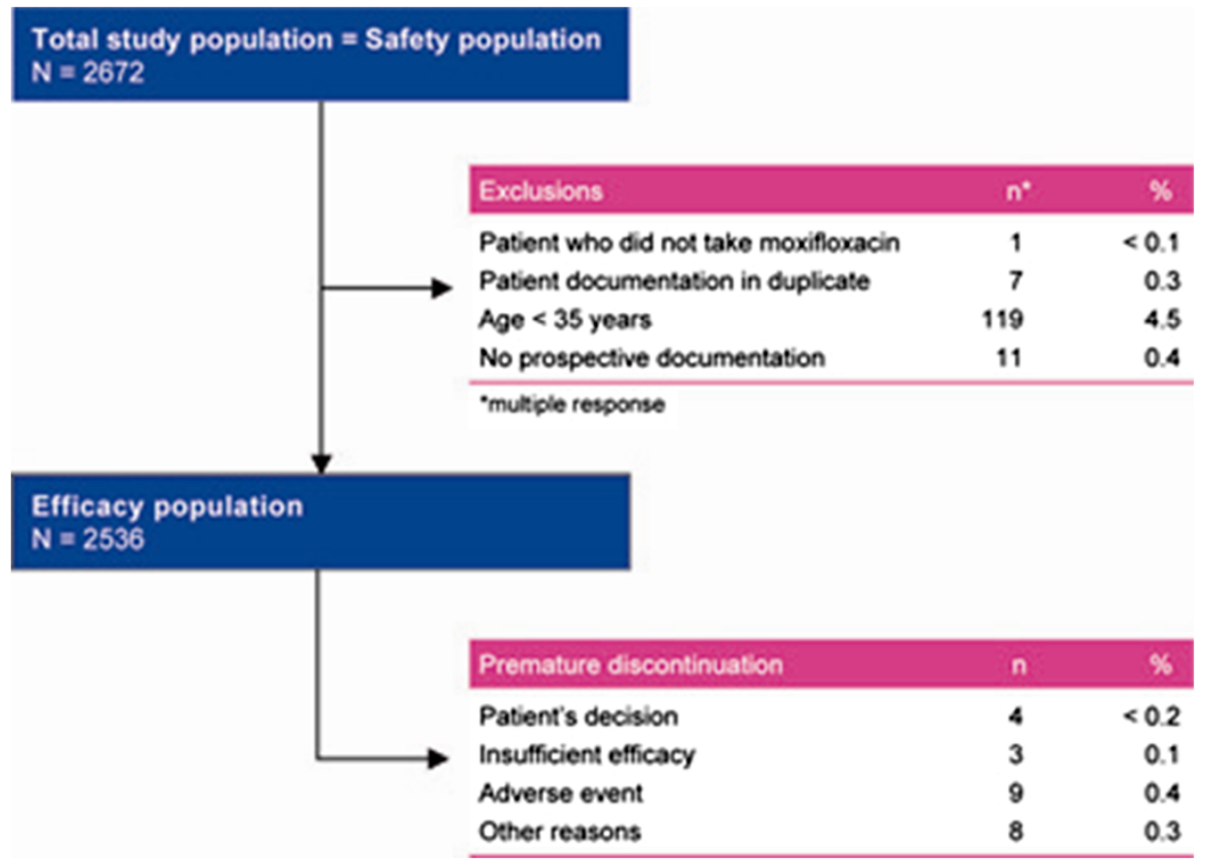

Figure 1 Patient disposition.

one-half of patients (53.9\%) were past or current smokers. Over the past 12 months, patients had experienced a mean of $2.7 \pm 1.9$ (range 1.0-20.0) episodes of AECB. An antibiotic was prescribed for the previous episode of AECB in $62.2 \%$ of patients, most commonly amoxicillin (13.6\% of patients), usually combined with clavulanic acid.

The most common symptoms in the current AECB episode were increased sputum purulence, worsening of dyspnea, and increased sputum volume (Table 1); 42.9\% of patients were classified as Anthonisen type I, 40.2\% as type II, and $16.2 \%$ as type III, with data missing in the remainder (Table 1). One-half of patients (49.9\%) complained of an infection of the upper respiratory tract in the past 5 days. An impact on daily life activities was reported by $90.4 \%$, over a mean duration of $6.6 \pm 5.5$ days. Sleep disturbances were reported by $68.6 \%$ of patients, with impact on a mean of $4.1 \pm 3.7$ nights. The impact of the current AECB episode on daily activities and sleep disturbance in patient subgroups categorized by gender, age, smoking status, concomitant diseases, Anthonisen grade, and number of severe symptoms is presented in Table 2. Mean $\mathrm{FEV}_{1}$ (measured in 1261 patients) was $2.0 \pm 0.9$ liters. Patients experienced AECB symptoms for a mean of $7.0 \pm 5.0$ days before initiation of treatment with moxifloxacin.

Concomitant diseases of special interest recorded by investigators included COPD (66.0\% of patients), emphysema $(23.8 \%)$, asthma (16.6\%), cardiac ischemia (23.1\%), cor pulmonale $(10.6 \%)$, and diabetes $(10.1 \%)$. Concomitant medications were taken by $93.3 \%$ of patients, most commonly a corticosteroid $(32.8 \%$ overall, including $40.8 \%$ of Anthonisen type I, $28.0 \%$ of type II, and $24.2 \%$ of type III patients); the mucolytic ambroxol (18.8\%); and the mucolytic/antioxidant, acetylcysteine (18.6\%). As expected, a large proportion of patients $(83.4 \%)$ received comedications to treat their respiratory symptoms.

The most frequently used non-AECB-related comedications were for the treatment of cardiovascular symptoms (36.1\% of patients), dermatological diseases (23.0\%), dysfunction of the alimentary tract and metabolism (22.2\%), and ophthalmological diseases (20.5\%).

\section{Moxifloxacin treatment}

Moxifloxacin was administered at the recommended dose of $400 \mathrm{mg}$ once daily in $99.6 \%(\mathrm{n}=2526)$ of enrolled patients, with a higher dose of $600 \mathrm{mg} /$ day $(\mathrm{n}=5)$ or $800 \mathrm{mg} /$ day $(\mathrm{n}=5)$ in the remainder.

The mean (SD) duration of moxifloxacin treatment was $6.4 \pm 1.9$ days (range: $1.0-15.0$ days) in the efficacy population; $55.2 \%$ of patients were treated for 5 days, $29.1 \%$ for 7 days, and $14.0 \%$ for 10 days. Mean durations of treatment in patients with Anthonisen type I, type II, and type III AECB were $6.4 \pm 1.9,6.4 \pm 1.9$, and $6.2 \pm$ 1.8 days, respectively, and were $6.3 \pm 1.9$ days in never smokers versus $6.5 \pm 1.9$ days in past or current smokers. Durations of treatment were $6.0 \pm 1.8$ days for patients aged $<50$ years, $6.4 \pm 1.9$ for age $\geq 50$ to $<65,6.7 \pm 2.0$ days for age $\geq 65$ to $<80$, and $7.0 \pm 1.9$ days for age $\geq 80$ years.

The last follow-up visit was performed after a mean of $9.8 \pm 6.2$ days (range 2-66 days) from the initiation of 
Table 1 Patient demographics and disease characteristics at baseline (efficacy population)

\begin{tabular}{|c|c|}
\hline Parameter & $\begin{array}{c}\text { Total } N=2536 \\
(100 \%)\end{array}$ \\
\hline \multicolumn{2}{|l|}{ Gender, n (\%) } \\
\hline Male & $1441(56.8)$ \\
\hline Female & $1095(43.2)$ \\
\hline Mean (SD) age, y $(n=2532)$ & $57.8(12.2)$ \\
\hline Mean (SD) weight, $\mathrm{kg}(\mathrm{n}=2504)$ & $78.8(15.3)$ \\
\hline Mean (SD) height, $\mathrm{cm}(\mathrm{n}=2477)$ & $170.4(8.5)$ \\
\hline Mean (SD) BMl, kg/m² $(n=2477)$ & $27.1(4.8)$ \\
\hline \multicolumn{2}{|l|}{ Race, n (\%) } \\
\hline White & $2349(92.6)$ \\
\hline Asian & $73(2.9)$ \\
\hline Black & $7(0.3)$ \\
\hline Other & $6(0.2)$ \\
\hline Missing & $101(4.0)$ \\
\hline \multicolumn{2}{|l|}{ Frequency of common symptoms, n (\%) } \\
\hline Sputum purulence increased & $2021(79.7)$ \\
\hline Worsening dyspnea & $1998(78.8)$ \\
\hline Sputum volume increased & $1707(67.3)$ \\
\hline Upper respiratory tract infection (past 5 days) & $1266(49.9)$ \\
\hline \multicolumn{2}{|l|}{ Anthonisen grade, $\mathrm{n}(\%)$} \\
\hline Type I & $1089(42.9)$ \\
\hline Type ॥ & $1019(40.2)$ \\
\hline Type III & $412(16.2)$ \\
\hline Missing & $16(0.6)$ \\
\hline \multicolumn{2}{|l|}{ Smoking status, n (\%) } \\
\hline Past or current & $1367(53.9)$ \\
\hline Never & $1159(45.7)$ \\
\hline Missing & $10(0.4)$ \\
\hline \multicolumn{2}{|l|}{ Years with chronic bronchitis, n (\%) } \\
\hline$<1$ & $127(5.0)$ \\
\hline $1-5$ & $863(34.0)$ \\
\hline$>5-10$ & $748(29.5)$ \\
\hline$>10$ & $796(31.4)$ \\
\hline Missing & $2(0.1)$ \\
\hline \multicolumn{2}{|l|}{ Exacerbations in past 12 months } \\
\hline None & $478(18.8)$ \\
\hline Yes & $2048(80.8)$ \\
\hline 1 & $479(18.9)$ \\
\hline 2 & $745(29.4)$ \\
\hline 3 & $420(16.6)$ \\
\hline 4 & $198(7.8)$ \\
\hline 5 & $97(3.8)$ \\
\hline$\geq 6$ & $109(4.3)$ \\
\hline Missing & $10(0.4)$ \\
\hline \multicolumn{2}{|l|}{ Hospitalization due to $A E C B$ in past 12 months } \\
\hline None & $1867(73.6)$ \\
\hline
\end{tabular}

Table 1 Patient demographics and disease characteristics at baseline (efficacy population) (Continued)

\begin{tabular}{lc}
\hline Yes & $668(26.3)$ \\
\hline 1 & $442(17.4)$ \\
\hline 2 & $164(6.5)$ \\
\hline 3 & $35(1.4)$ \\
\hline 4 & $10(0.4)$ \\
\hline$\geq 5$ & $17(0.7)$ \\
\hline Missing & $1(<0.1)$ \\
\hline Yes & \\
\hline No & $964(38.0)$ \\
\hline Missing & $1571(61.9)$ \\
\hline Antibiotic treatment for last AECB & $1(<0.1)$ \\
\hline Yes & $1577(62.2)$ \\
\hline No & $959(37.8)$ \\
\hline Missing & $0(0.0)$ \\
\hline AECB acute exacerbation of chronic bronchitis.
\end{tabular}

moxifloxacin treatment. Moxifloxacin was discontinued prematurely in $23(0.9 \%)$ patients, because of the patient's decision $(n=4)$, insufficient efficacy $(n=3)$, adverse events $(n=9)$, and 'other reasons' $(n=8)$ (multiple responses included).

\section{Efficacy assessments of moxifloxacin treatment}

An improvement or relief of the symptoms of AECB that were present at baseline was reported in $89.4 \%$ of patients for sputum volume, $97.2 \%$ for fever, $86.0 \%$ for cough, $87.7 \%$ for dyspnea, and $77.2 \%$ for sputum character during moxifloxacin treatment. Additional symptom changes are presented in Table 3.

Improvement in symptoms occurred after a mean of $3.4 \pm 1.4$ days of moxifloxacin treatment. Improvements occurred by 3 days in $60.7 \%$ of patients, 5 days in $93.2 \%$, and 10 days in $99.3 \%$. Only $0.6 \%$ of patients $(n=14)$ experienced no symptom improvements during the observational period.

The mean duration of treatment until symptom improvement in patients with Anthonisen type I, II, and III $\mathrm{AECB}$ was $3.6 \pm 1.5,3.3 \pm 1.4$, and $3.4 \pm 1.4$ days, respectively (Table 4), $3.4 \pm 1.4$ days in never smokers versus $3.5 \pm 1.5$ days in past or current smokers, $3.6 \pm 1.6$ days in concomitant corticosteroid users versus $3.4 \pm 1.3$ in noncorticosteroid users, and $3.7 \pm 1.5$ days in patients with $>3$ exacerbations versus $3.4 \pm 1.4$ days in patients with $\leq 3$ exacerbations in the previous 12 months. Duration of treatment until symptom improvement was $3.2 \pm 1.4$ days in patients aged $<50$ years, $3.4 \pm 1.4$ days for age $\geq 50$ to $<65,3.6 \pm 1.5$ days for age $\geq 65$ to $<80$, and $3.7 \pm 1.9$ for age $\geq 80$ years. Mean duration of treatment until symptom improvement in patients with concomitant diseases is 
Table 2 Impact of current AECB episode on daily life activities and sleep disturbance (efficacy population) Parameter

Days with impact on daily life activities

\begin{tabular}{ccc}
\hline & $(\mathrm{N}=2292)$ \\
\hline $\mathrm{n}(\%)$ & Mean & SD
\end{tabular}

\section{Gender}

Male

Female

Missing

Age group (years)

\begin{tabular}{l}
$\geq 35$ to $<50$ \\
$\geq 50$ to $<65$ \\
$\geq 65$ to $<80$ \\
$\geq 80$ \\
\hline Missing \\
Smoking status \\
Never \\
\hline Past or current smoker \\
\hline Missing \\
Concomitant diseases of special interest
\end{tabular}

\begin{tabular}{|c|c|c|c|c|c|c|}
\hline COPD & 1549 (67.6) & 6.6 & 5.6 & $1216(69.9)$ & 4.3 & 3.9 \\
\hline Asthma & $389(17.0)$ & 7.5 & 6.8 & $331(19.0)$ & 4.4 & 3.5 \\
\hline Emphysema & $568(24.8)$ & 7.7 & 6.4 & $461(26.5)$ & 4.5 & 3.7 \\
\hline Bronchiectasis & $151(6.6)$ & 7.3 & 6.9 & $128(7.4)$ & 4.6 & 4.7 \\
\hline Cor pulmonale & $251(11.0)$ & 8.1 & 6.4 & $222(12.8)$ & 5.1 & 4.2 \\
\hline Cardiomyopathy & $146(6.4)$ & 7.9 & 7.4 & $122(7.0)$ & 5.4 & 5.0 \\
\hline Cardiac ischemia & $544(23.7)$ & 7.2 & 6.3 & $429(24.7)$ & 4.2 & 3.5 \\
\hline Heart insufficiency & $135(5.9)$ & 10.9 & 10.1 & $126(7.2)$ & 6.4 & 6.3 \\
\hline Cardiac arrhythmia & $145(6.3)$ & 7.7 & 5.1 & $131(7.5)$ & 4.9 & 4.0 \\
\hline Chronic alcoholism & $39(1.7)$ & 6.0 & 6.8 & $24(1.4)$ & 5.3 & 5.5 \\
\hline Diabetes & $238(10.4)$ & 6.3 & 5.3 & $196(11.3)$ & 4.1 & 3.2 \\
\hline No diseases of special interest & $324(14.1)$ & 5.8 & 4.1 & $203(11.7)$ & 3.0 & 2.8 \\
\hline \multicolumn{7}{|l|}{ Anthonisen grade } \\
\hline Type I & $1014(44.2)$ & 7.1 & 5.1 & $793(45.6)$ & 4.5 & 3.8 \\
\hline Type ॥ & $913(39.8)$ & 6.5 & 5.9 & $666(38.3)$ & 3.8 & 3.6 \\
\hline Type III & $353(15.4)$ & 5.6 & 5.6 & $274(15.7)$ & 3.6 & 3.3 \\
\hline Missing & $12(0.5)$ & 7.4 & 6.2 & $7(0.4)$ & 7.3 & 7.5 \\
\hline \multicolumn{7}{|c|}{ Number of severe symptoms per patient at start of therapy } \\
\hline 1 & $446(19.5)$ & 6.0 & 5.2 & $295(17.0)$ & 3.5 & 3.5 \\
\hline 2 & $596(26.0)$ & 6.0 & 5.0 & $417(24.0)$ & 3.5 & 3.3 \\
\hline 3 & $377(16.4)$ & 6.3 & 5.0 & $279(16.0)$ & 4.1 & 3.1 \\
\hline 4 & $241(10.5)$ & 6.8 & 5.4 & $193(11.1)$ & 4.4 & 3.9 \\
\hline 5 & $163(7.1)$ & 7.7 & 4.9 & $142(8.2)$ & 4.9 & 3.4 \\
\hline 6 & $142(6.2)$ & 10.2 & 7.9 & 141 (8.1) & 5.8 & 3.7 \\
\hline 7 & $66(2.9)$ & 9.6 & 7.5 & $66(3.8)$ & 6.2 & 5.8 \\
\hline 8 & $16(0.7)$ & 10.4 & 9.6 & $15(0.9)$ & 8.1 & 8.6 \\
\hline None & $245(10.7)$ & 5.6 & 4.6 & $192(11.0)$ & 3.2 & 3.1 \\
\hline
\end{tabular}

$\mathrm{AECB}$, acute exacerbation of chronic bronchitis; COPD, chronic obstructive pulmonary disease.

Nights with sleep disturbance

\begin{tabular}{|rr} 
& $(\mathrm{N}=1740)$ \\
\hline $\mathrm{n}(\%)$ & Mean $\quad$ SD
\end{tabular}

\begin{tabular}{cccccc}
$1308(57.1)$ & 6.6 & 5.3 & $971(55.8)$ & 4.1 & 3.8 \\
\hline $984(42.9)$ & 6.6 & 5.8 & $769(44.2)$ & 4.1 & 3.6 \\
\hline $0(0)$ & - & - & $0(0)$ & - & -
\end{tabular}

\begin{tabular}{cccccc}
$615(26.8)$ & 6.4 & 5.2 & $406(23.3)$ & 3.7 & 2.7 \\
\hline $922(40.2)$ & 6.7 & 5.9 & $712(40.9)$ & 4.0 & 4.1 \\
\hline $680(29.7)$ & 6.7 & 5.3 & $557(32.0)$ & 4.5 & 3.8 \\
\hline $71(3.1)$ & 5.8 & 3.9 & $63(3.6)$ & 4.3 & 3.0 \\
\hline $4(0.2)$ & 11.8 & 5.2 & $2(0.1)$ & 4.0 & 1.4 \\
\hline
\end{tabular}

\begin{tabular}{cccccc}
$1027(44.8)$ & 6.7 & 5.6 & $786(45.2)$ & 4.0 & 3.7 \\
\hline $1255(54.8)$ & 6.5 & 5.4 & $945(54.3)$ & 4.2 & 3.7 \\
\hline $10(0.4)$ & 8.7 & 5.3 & $9(0.5)$ & 3.6 & 2.1 \\
\hline
\end{tabular}


Table 3 Course of symptoms during observational period; patients with symptoms at initial visit (efficacy population)

\begin{tabular}{|c|c|c|c|c|c|c|}
\hline Symptom & $\begin{array}{c}\text { Total } \\
\mathrm{n}(\%)^{\mathrm{a}}\end{array}$ & $\frac{\text { Relieved }}{\mathrm{n}(\%)^{\mathbf{b}}}$ & $\frac{\text { Improved }}{\mathrm{n}(\%)^{\mathrm{b}}}$ & $\frac{\text { Unchanged }}{\mathrm{n}(\%)^{\mathbf{b}}}$ & $\frac{\text { Worsened }}{n(\%)^{b}}$ & $\frac{\text { Missing }}{\mathrm{n}(\%)^{\mathrm{b}}}$ \\
\hline Fever & $1768(69.7)$ & $1713(96.9)$ & $5(0.3)$ & $15(0.8)$ & $0(0.0)$ & $35(2.0)$ \\
\hline Cough & $2512(99.1)$ & $1666(66.3)$ & 495 (19.7) & $320(12.7)$ & $1(<0.1)$ & $30(1.2)$ \\
\hline Dyspnea & $2298(90.6)$ & $1615(70.3)$ & $399(17.4)$ & $245(10.7)$ & $1(<0.1)$ & $38(1.7)$ \\
\hline Sputum volume & $2471(97.4)$ & $1364(55.2)$ & $846(34.2)$ & $226(9.1)$ & $8(0.3)$ & $27(1.1)$ \\
\hline Sputum character & $2284(90.1)$ & $1350(59.1)$ & 446 (19.5) & $73(3.2)$ & $1(<0.1)$ & $414(18.1)$ \\
\hline Chest discomfort & $2116(83.4)$ & $1822(86.1)$ & $103(4.9)$ & $152(7.2)$ & $1(<0.1)$ & $38(1.8)$ \\
\hline Fatigue & $1984(78.2)$ & $1573(79.3)$ & $180(9.1)$ & $186(9.4)$ & $0(0.0)$ & $45(2.3)$ \\
\hline Sleep disturbances & $1672(65.9)$ & $1521(91.0)$ & $45(2.7)$ & $78(4.7)$ & $1(0.1)$ & $27(1.6)$ \\
\hline
\end{tabular}

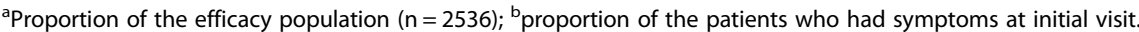

described in Table 4. For patients with COPD (diagnosed by the attending physician), the mean duration of moxifloxacin treatment until improvement was $3.5 \pm 1.4$ days.

The mean duration until attainment of a symptom-free status was $6.5 \pm 2.7$ days. A total of $49.1 \%$ of patients were symptom-free after 5 days, $77.6 \%$ after 7 days, $93.5 \%$ after 10 days, and $98.3 \%$ after 20 days (Figure 2). Only $1.4 \%$ of observed patients $(n=36)$ were reported not to attain symptom-free status during the observational period.

\section{Safety assessments}

Treatment-emergent adverse events (TEAEs) were reported in $2.13 \%(\mathrm{n}=57)$ patients during the observational period. The most common TEAEs included diarrhea $(0.52 \%, \mathrm{n}=14$ patients $)$, nausea $(0.41 \%, \mathrm{n}=11)$, dizziness

Table 4 Duration of treatment until symptom improvement (efficacy population)

\begin{tabular}{llll}
\hline Parameter & \multicolumn{3}{c}{$\begin{array}{c}\text { Duration until } \\
\text { improvement }\end{array}$} \\
\cline { 2 - 4 } & $\mathbf{n}$ & Mean & SD \\
\hline Anthonisen grade & & & \\
\hline Type I & 1084 & 3.6 & $(1.5)$ \\
\hline Type II & 1011 & 3.3 & $(1.4)$ \\
\hline Type III & 409 & 3.4 & $(1.4)$ \\
\hline Missing & 16 & 4.2 & $(1.6)$ \\
\hline Concomitant diseases of special interest & & & \\
\hline COPD & 1667 & 3.5 & 1.4 \\
\hline Asthma & 412 & 3.4 & 1.4 \\
\hline Emphysema & 602 & 3.6 & 1.5 \\
\hline Bronchiectasis & 162 & 3.8 & 1.4 \\
\hline Cor pulmonale & 268 & 3.6 & 1.4 \\
\hline Cardiomyopathy & 157 & 3.5 & 1.5 \\
\hline Cardiac ischemia & 582 & 3.7 & 1.6 \\
\hline Heart insufficiency & 138 & 3.1 & 1.3 \\
\hline Cardiac arrhythmia & 151 & 3.7 & 1.6 \\
\hline Diabetes & 255 & 3.6 & 1.7 \\
\hline COPD, chronic obstructive pulmonary disease. & & &
\end{tabular}

COPD, chronic obstructive pulmonary disease.
$(0.30 \%, \mathrm{n}=8)$, dyspepsia $(0.22 \%, \mathrm{n}=6)$, fatigue $(0.15 \%$, $\mathrm{n}=4)$, and headache $(0.15 \%, \mathrm{n}=4)$. TEAEs considered potentially drug related were reported in $1.91 \%(n=51)$ patients. Moxifloxacin treatment was interrupted in eight of these patients, withdrawn in four, and the dose was reduced in one patient. By the end of the observational period, drug-related TEAEs had resolved in 40 of the 51 patients, resolved with sequelae in another three, and improved in eight patients.

Four patients $(0.15 \%)$ experienced 11 serious TEAEs $(\mathrm{n}=2$, atrial fibrillation; $\mathrm{n}=1$ each of: acute myocardial infarction, cardiac flutter, diplopia, vomiting, allergic edema, amnesia, dizziness, dyspnea, and skin reaction). The serious TEAEs were considered to be drug related. All serious TEAEs had resolved by the end of the observational period, following interruption of moxifloxacin treatment in three patients and treatment withdrawal in one patient.

None of the 10 patients who received moxifloxacin at above the recommended dose of $400 \mathrm{mg}$ once daily $(\mathrm{n}=5$, $600 \mathrm{mg} /$ day; $\mathrm{n}=5,800 \mathrm{mg} /$ day) experienced an adverse event.

\section{Summary assessments of moxifloxacin treatment}

The efficacy of moxifloxacin was rated by physicians as 'very good' or 'good' in $97.7 \%$ of patients, 'sufficient' in $1.8 \%$, and 'insufficient' in $0.5 \%$. Physicians' assessments of the efficacy of moxifloxacin in patient subgroups categorized by gender, age, and Anthonisen grade are presented in Table 5. The tolerability of moxifloxacin was rated by physicians as 'very good' or 'good' in $97.8 \%$ of patients, 'sufficient' in 1.8\%, and 'insufficient' in $0.3 \%$.

Approximately $99 \%$ of both physicians and patients stated that they were 'very satisfied' or 'satisfied' with the therapeutic effect of moxifloxacin. Compared with the antibiotic treatment during the previous episode of $\mathrm{AECB}$, physicians rated moxifloxacin as better in $77.5 \%$ of patients, equal in $5.3 \%$, and worse in $0.2 \%$, with missing data in $17.0 \%$. Moxifloxacin was considered to have an earlier onset of action compared with the previous 


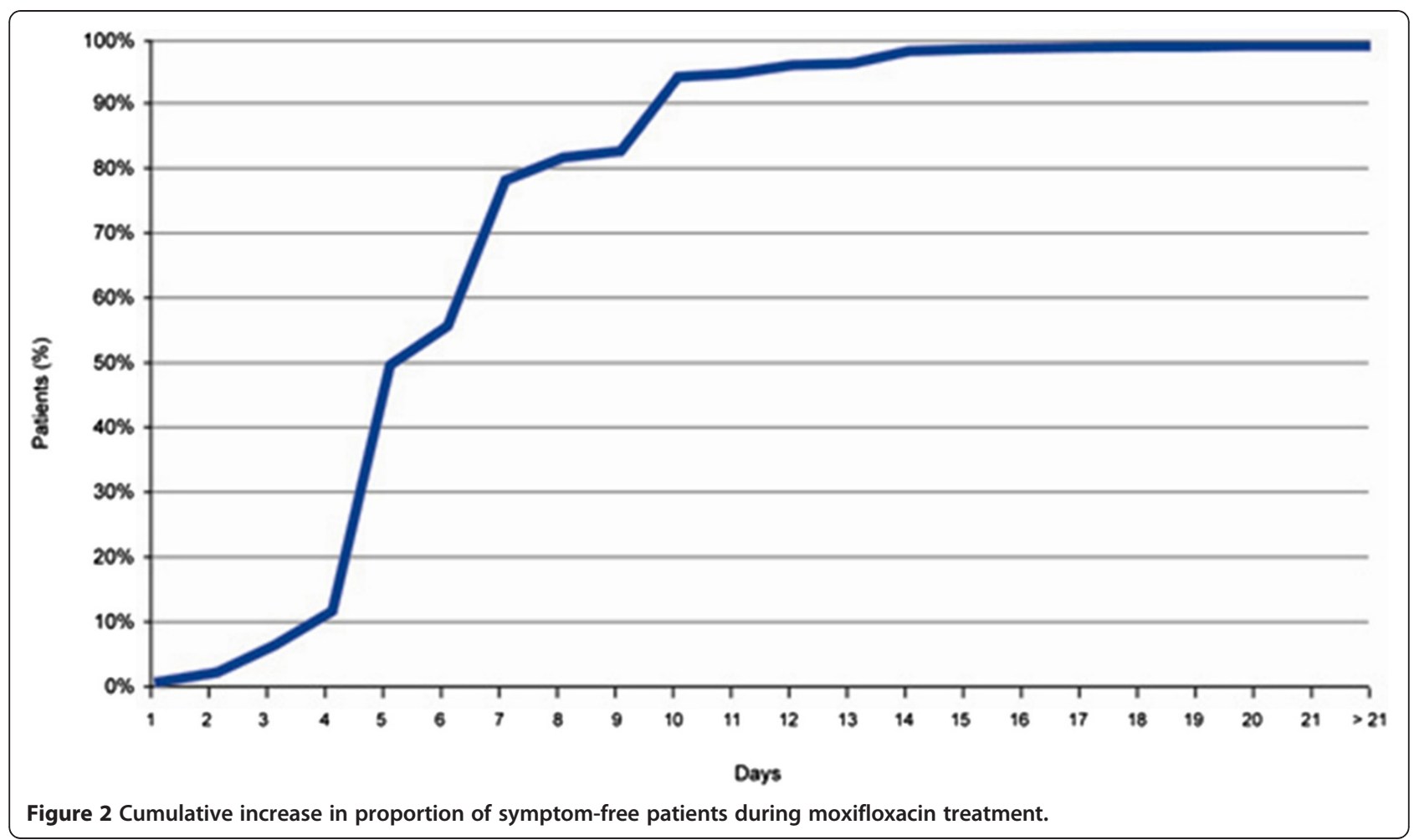

antibiotic in $73.5 \%$ of patients, equivalent onset in $9.5 \%$, and later onset in 1.3\%, with missing data in $15.7 \%$. Physicians reported that they would prescribe moxifloxacin again in $98.1 \%$ of patients.

\section{Discussion}

This non-interventional, naturalistic observational study enrolled a large cohort of outpatients $(n=2672)$ with

Table 5 Physician's assessments of efficacy of moxifloxacin (efficacy population)

\begin{tabular}{|c|c|c|c|c|}
\hline Parameter & $\frac{\text { Total }}{\mathrm{n}}$ & $\frac{\text { Very good / good }}{\mathrm{n}(\%)}$ & $\frac{\text { Sufficient }}{\mathrm{n}(\%)}$ & $\frac{\text { Insufficient }}{\mathrm{n}(\%)}$ \\
\hline \multicolumn{5}{|l|}{ Gender } \\
\hline Male & 1441 & $1405(97.5)$ & $30(2.1)$ & $6(0.4)$ \\
\hline Female & 1095 & $1072(97.9)$ & $15(1.4)$ & $7(0.6)$ \\
\hline Missing & 0 & $0(0)$ & $0(0)$ & $0(0)$ \\
\hline \multicolumn{5}{|c|}{ Age group (years, $n=2462$ ) } \\
\hline$\geq 35$ to $<50$ & 707 & $694(98.2)$ & $9(1.3)$ & $4(0.6)$ \\
\hline$\geq 50$ to $<65$ & 1023 & $999(97.7)$ & $20(2.0)$ & $4(0.4)$ \\
\hline$\geq 65$ to $<80$ & 728 & $707(97.1)$ & $15(2.1)$ & $5(0.7)$ \\
\hline Missing & 4 & $4(100)$ & $0(0)$ & $0(0)$ \\
\hline \multicolumn{5}{|c|}{ Anthonisen grade } \\
\hline Type I & 1089 & $1065(97.8)$ & $17(1.6)$ & $7(0.6)$ \\
\hline Type II & 1019 & $995(97.6)$ & $21(2.1)$ & $3(0.3)$ \\
\hline Type III & 412 & $401(97.3)$ & $7(1.7)$ & $3(0.7)$ \\
\hline Missing & 16 & $16(100)$ & $0(0)$ & $0(0)$ \\
\hline
\end{tabular}

AECB, Anthonisen types I to III, to receive moxifloxacin treatment at the recommended dose of $400 \mathrm{mg}$ once daily. A special feature of the study is the welldocumented patient history regarding previous AECBs, concomitant diseases, and comedications related both to the underlying respiratory disease as well as to other comorbidities before study entry. The majority of patients (approximately 80\%) had experienced an exacerbation within the previous 12 months. Also reflecting current clinical experience, a large proportion of the patients had an underlying respiratory condition (e.g. COPD, emphysema, or asthma).

Moxifloxacin administered for a mean of 6.4 days (range 1-15 days) was a highly effective treatment in these patients. Individual symptoms and signs of sputum volume, fever, cough, dyspnea, and sputum character resolved or improved in the majority of patients (range 77-89\%) during the observational period. Improvements in symptoms occurred after a mean of 3.4 days and over 93\% of patients were symptom-free after 10 days. No differences in the efficacy of moxifloxacin were observed between patients either without or with a diverse range of comorbidities.

Unlike in clinical trials, the dosing regimen used in this non-interventional study was left to the sole discretion of the treating physician. It is interesting to note the high rate of physician compliance (99.6\%) with the dose recommended in the Summary of Product Characteristics. This suggests that physicians considered the recommended 
dose of moxifloxacin to be highly effective, without the need to adjust the dose, e.g. for body weight. The lack of need for dose adjustment has the advantages of easier dosing and a reduced risk of overdosing.

The results of this study are in agreement with previous studies of moxifloxacin treatment in patients with $\mathrm{AECB}$, including the international observational GIANT study, where symptom improvement occurred after a mean of 3.4 days [29]. Physicians' summary assessments of moxifloxacin were also similar in the two studies, including a rating of 'very good or good' in excess of $95 \%$ of patients.

The rapid recovery from symptoms observed in this study is a desirable characteristic of an effective treatment for patients with AECB. Other observational and controlled studies and cross-sectional analyses report that moxifloxacin is associated with a more rapid recovery from symptoms than other commonly used treatments [31-33]. The mean duration of treatment until symptom improvement in the current study was broadly similar among patients, but with a trend to increased treatment duration in patients with greater AECB severity, concomitant diseases, and older age.

Physicians rated the tolerability of moxifloxacin as 'very good or good' in approximately $98 \%$ of patients, similar to the rate $(97 \%)$ reported in the observational study by Miravitlles et al. [29]. Incidences of TEAEs and drug-related adverse events were low. The incidence of TEAEs was lower in the current study than reported in controlled clinical studies (e.g. [34]), which may be attributed to an underreporting of mild/moderate adverse events that is a feature of observational studies.

The profile of adverse events reported in this study is in agreement with current knowledge of this antibiotic $[25,29,35,36]$. A meta-analysis of clinical trial and postmarketing surveillance data for moxifloxacin identified nausea, dizziness, and diarrhea as the most frequent adverse events, which occurred at a rate similar to comparator medications [35]. For most patients in the current study, adverse events resolved during the course of treatment and were associated with low rates of treatment withdrawal $(0.4 \%)$. The observational study by Miravitlles et al. [29] reported similarly low rates of treatment-related withdrawal $(0.6 \%)$.

The overall satisfaction with moxifloxacin treatment expressed by both physicians and patients was high. Relative to previous antibiotics, moxifloxacin also provided a superior efficacy and a faster onset of effect in the majority of patients.

Notable demographic and disease characteristics of this population from South Eastern/Eastern Europe include a markedly higher incidence of COPD among non-smokers when compared with data from Western Europe and the USA [37-39]. This indicates that additional environmental factors, such as high levels of industrial air pollution and/or occupational or home indoor air pollution, contributed to the development of COPD in patients from the participating countries, as described by Mannino and Buist [40].

Limitations of the current study include the primary role of physician judgment for decisions on patient selection and management; the absence of a control group to quantify the response to other antibacterial agents; and the lack of bacteriological assessment, which precludes a correlation with the clinical outcomes. All prescribing choices were made by physicians. As approximately $16 \%$ of patients who received moxifloxacin were classified with Anthonisen type III AECB, antibiotic therapy was not prescribed in accordance with current guidelines in all circumstances. A similar experience was reported in the GIANT study [29].

A strength of observational studies is that they provide an important accompaniment to randomized controlled trials and reflect real-world practice in terms of prescribing behavior [41]. The lack of bacteriological assessment in this study is in line with current practice for the outpatient treatment of AECB. The high response rate in this study, which included patients with a range of common comorbidities, suggests that treatment with broader-spectrum drugs such as moxifloxacin is appropriate for patients with moderate-to-severe AECB who are managed outside hospital.

\section{Conclusions}

The efficacy, safety, and tolerability profiles of moxifloxacin that are characterized in this large observational study from South Eastern/Eastern Europe confirm previous studies which report that moxifloxacin offers benefits for the treatment of moderate-to-severe exacerbations in outpatients with AECB. The response to moxifloxacin treatment was broadly independent of the patients' demographic and disease background. Physicians complied with the recommended $400 \mathrm{mg}$ once-daily dose in a large proportion of patients, confirming the advantages of this simple dosing regimen.

\section{Abbreviations}

AECB: Acute exacerbation of chronic bronchitis; AECOPD: Acute exacerbation of chronic obstructive pulmonary disease; COPD: Chronic obstructive pulmonary disease; $\mathrm{FEV}_{1}$ : Forced expiratory volume in 1 second.

\section{Competing interests}

$A C, M Z, D D$, and $M T$ declare that they have no competing interests. $\mathrm{H}-\mathrm{PM}$ and TP are full-time employees of Bayer AG.

\section{Authors' contributions}

AC participated in study design, data acquisition, and data analysis and interpretation. MZ, DD, MT, and H-PM participated in data acquisition and data analysis and interpretation. TP participated in study design and concepts, and data analysis and interpretation. All authors participated in the critical review revision of the manuscript. All authors read and approved the final manuscript for submission. 


\section{Acknowledgments}

Bayer Pharma provided support in the design and conduct of the study and in the collection, management, and analysis of the data. The roles of the authors who are employed by Bayer Pharma are itemized in the section above

Caroline Schneider and Klaus Hechenbichler at the Dr. Schauerte Contract Research organization provided project management and statistical support. Bill Wolvey at PAREXEL provided medical writing support funded by Bayer Pharma.

\section{Author details}

'Pulmonology Department, Federal State Institution "Research Institute of Pulmonology of Roszdrav", Moscow 105077, Russian Federation.

${ }^{2}$ Pulmonology Department, Hospital \#7, Simferopol 95044, Ukraine. ${ }^{3}$ Klinika za Pulmologija i Alergologija, Skopje 1000, Macedonia. ${ }^{4}$ Privatna Pulmološka Ordinacija "Dr. Tokić", 71000 Sarajevo, Bosnia and Herzegovina. ${ }^{5}$ Bayer Vital GmbH, Leverkusen 51368, Germany. ${ }^{6}$ Bayer Pharma AG, Berlin 13353, Germany.

Received: 7 June 2012 Accepted: 16 January 2013

Published: 23 January 2013

\section{References}

1. Celli BR, Thomas NE, Anderson JA, Ferguson GT, Jenkins CR, Jones PW, Vestbo J, Knobil K, Yates JC, Calverley PM: Effect of pharmacotherapy on rate of decline of lung function in chronic obstructive pulmonary disease: results from the TORCH study. Am J Respir Crit Care Med 2008, 178(4):332-338.

2. Doll H, Miravitlles M: Health-related QOL in acute exacerbations of chronic bronchitis and chronic obstructive pulmonary disease: a review of the literature. PharmacoEconomics 2005, 23(4):345-363.

3. Donaldson GC, Seemungal TA, Bhowmik A, Wedzicha JA: Relationship between exacerbation frequency and lung function decline in chronic obstructive pulmonary disease. Thorax 2002, 57(10):847-852.

4. Kanner RE, Anthonisen NR, Connett JE: Lower respiratory illnesses promote $\mathrm{FEV}(1)$ decline in current smokers but not ex-smokers with mild chronic obstructive pulmonary disease: results from the lung health study. Am J Respir Crit Care Med 2001, 164(3):358-364.

5. Nicolson P, Anderson P: The patient's burden: physical and psychological effects of acute exacerbations of chronic bronchitis. J Antimicrob Chemother 2000, 45:25-32.

6. Seemungal TA, Donaldson GC, Paul EA, Bestall JC, Jeffries DJ, Wedzicha JA: Effect of exacerbation on quality of life in patients with chronic obstructive pulmonary disease. Am J Respir Crit Care Med 1998, 157(5 Pt 1):1418-1422.

7. Soler-Cataluna JJ, Martinez-Garcia MA, Roman SP, Salcedo E, Navarro M, Ochando R: Severe acute exacerbations and mortality in patients with chronic obstructive pulmonary disease. Thorax 2005, 60(11):925-931.

8. Spencer S, Jones PW: Time course of recovery of health status following an infective exacerbation of chronic bronchitis. Thorax 2003, 58(7):589-593.

9. Sethi S: Infectious etiology of acute exacerbations of chronic bronchitis. Chest 2000, 117(5 Suppl 2):380S-385S.

10. Global Initative for Chronic Obstructive Lung Disease (GOLD): Global Strategy for the Diagnosis, Management and Prevention of COPD; 2010. Available at: http://www.goldcopd.org/guidelines-global-strategy-fordiagnosis-management.html. Accessed November 1, 2011.

11. O'Donnell DE, Hernandez P, Kaplan A, Aaron S, Bourbeau J, Marciniuk D, Balter M, Ford G, Gervais A, Lacasse Y, Maltais F, Road J, Rocker G, Sin D, Sinuff T, Voduc N: Canadian Thoracic Society recommendations for management of chronic obstructive pulmonary disease - 2008 update highlights for primary care. Can Respir J 2008, 15(Suppl A):1A-8A.

12. Woodhead M, Blasi F, Ewig S, Garau J, Huchon G, leven M, Ortqvist A, Schaberg T, Torres A, van der Heijden G, Read R, Verheij TJ: Guidelines for the management of adult lower respiratory tract infections-full version. Clin Microbiol Infect 2011, 17(Suppl 6):E1-E59.

13. Anthonisen NR, Manfreda J, Warren CP, Hershfield ES, Harding GK, Nelson NA: Antibiotic therapy in exacerbations of chronic obstructive pulmonary disease. Ann Intern Med 1987, 106(2):196-204.

14. Burkhardt $\mathrm{O}$, Welte $\mathrm{T}: 10$ years' experience with the pneumococcal quinolone moxifloxacin. Expert Rev Anti Infect Ther 2009, 7(6):645-668.

15. Chodosh S, DeAbate CA, Haverstock D, Aneiro L, Church D: Short-course moxifloxacin therapy for treatment of acute bacterial exacerbations of chronic bronchitis.The bronchitis study group. Respir Med 2000, 94(1):18-27.
16. Miravitlles M, Molina J, Brosa M: Clinical efficacy of moxifloxacin in the treatment of exacerbations of chronic bronchitis: a systematic review and meta-analysis [in Spanish]. Arch Bronconeumol 2007, 43(1):22-28.

17. Wilson R, Kubin R, Ballin I, Deppermann KM, Bassaris HP, Leophonte P, Schreurs $\mathrm{A}$, Torres A, Sommerauer B: Five day moxifloxacin therapy compared with 7 day clarithromycin therapy for the treatment of acute exacerbations of chronic bronchitis. J Antimicrob Chemother 1999, 44(4):501-513.

18. Miravitlles M: Moxifloxacin: an antibiotic designed for use in the community. Eur Respir Rev 2000, 10:161-169.

19. Soman A, Honeybourne D, Andrews J, Jevons G, Wise R: Concentrations of moxifloxacin in serum and pulmonary compartments following a single $400 \mathrm{mg}$ oral dose in patients undergoing fibre-optic bronchoscopy. J Antimicrob Chemother 1999, 44(6):835-838.

20. Krasemann C, Meyer J, Springsklee M: Moxifloxacin (MFX) in acute exacerbations of chronic bronchitis (AECB): a bacteriological and clinical metaanalysis [abstract]: Program and abstracts of the 9th European Congress of Clinical Microbiology and Infectious Diseases; 1999. Abstract P203.

21. Miravitlles M: Moxifloxacin in respiratory tract infections. Expert Opin Pharmacother 2005, 6(2):283-293.

22. Wilson R, Allegra L, Huchon G, Izquierdo JL, Jones P, Schaberg T, Sagnier PP: Short-term and long-term outcomes of moxifloxacin compared to standard antibiotic treatment in acute exacerbations of chronic bronchitis. Chest 2004, 125(3):953-964.

23. Miravitlles M: Moxifloxacin in the management of exacerbations of chronic bronchitis and COPD. Int J Chron Obstruct Pulmon Dis 2007, 2(3):191-204.

24. Wilson R, Jones P, Schaberg T, Arvis P, Duprat-Lomon I, Sagnier PP: Antibiotic treatment and factors influencing short and long term outcomes of acute exacerbations of chronic bronchitis. Thorax 2006 61(4):337-342

25. Wilson R, Anzueto A, Miravitlles M, Arvis P, Alder J, Haverstock D, Trajanovic $M$, Sethi S: Moxifloxacin vs amoxicillin/clavulanic acid in outpatient AECOPD: MAESTRAL results. Eur Respir J 2012, Epub ahead of print.

26. Miravitlles M, Llor C, Molina J, Naberan K, Cots JM, Ros F: Antibiotic treatment of exacerbations of COPD in general practice: long-term impact on health-related quality of life. Int J Chron Obstruct Pulmon Dis 2010, 5:11-19.

27. Llor C, Sierra N, Hernandez S, Moragas A, Hernandez M, Bayona C, Miravitlles $\mathrm{M}$ : The higher the number of daily doses of antibiotic treatment in lower respiratory tract infection the worse the compliance. J Antimicrob Chemother 2009, 63(2):396-399.

28. Simoens S, Decramer M: A pharmacoeconomic review of the management of respiratory tract infections with moxifloxacin. Expert Opin Pharmacother 2008, 9(10):1735-1744.

29. Miravitlles M, Anzueto A, Ewig S, Legnani D, Stauch K: Characterisation of exacerbations of chronic bronchitis and COPD in Europe: the GIANT study. Ther Adv Respir Dis 2009, 3(6):267-277.

30. Merck: AVELOX ${ }^{\circledR}$ (moxifloxacin hydrochloride) US prescribing information; 2011. Available at: http://www.merck.com/product/usa/pi_circulars/a/avelox/ avelox_pi.pdf. Accessed January 25, 2012.

31. Miravitlles M, Zalacain R, Murio C, Ferrer M, Alvarez-Sala JL, Masa JF, Verea H, Ros F, Vidal R: Speed of recovery from acute exacerbations of chronic obstructive pulmonary disease after treatment with antimicrobials: results of a two-year study. Clin Drug Investig 2003, 23(7):439-450.

32. Miravitlles $M$, Torres A: Antibiotics in exacerbations of COPD: lessons from the past. Eur Respir J 2004, 24(6):896-897.

33. Kreis SR, Herrera N, Golzar N: A comparison of moxifloxacin and azithromycin in the treatment of acute exacerbations of chronic bronchitis. J Clin Outcomes Manage 2000, 7(12):33-37.

34. Sethi S, Jones PW, Theron MS, Miravitlles M, Rubinstein E, Wedzicha JA, Wilson R: Pulsed moxifloxacin for the prevention of exacerbations of chronic obstructive pulmonary disease: a randomized controlled trial. Respir Res 2010, 11:10.

35. Ball P, Stahlmann R, Kubin R, Choudhri S, Owens R: Safety profile of oral and intravenous moxifloxacin: cumulative data from clinical trials and postmarketing studies. Clin Ther 2004, 26(7):940-950.

36. Van Bambeke F, Tulkens PM: Safety profile of the respiratory fluoroquinolone moxifloxacin: comparison with other fluoroquinolones and other antibacterial classes. Drug Saf 2009, 32(5):359-378.

37. Behrendt CE: Mild and moderate-to-severe COPD in nonsmokers: distinct demographic profiles. Chest 2005, 128(3):1239-1244. 
38. Birring SS, Brightling CE, Bradding P, Entwisle JJ, Vara DD, Grigg J, Wardlaw AJ, Pavord ID: Clinical, radiologic, and induced sputum features of chronic obstructive pulmonary disease in nonsmokers: a descriptive study. Am J Respir Crit Care Med 2002, 166(8):1078-1083.

39. Pena VS, Miravitlles M, Gabriel R, Jimenez-Ruiz CA, Villasante C, Masa JF, Viejo JL, Fernandez-Fau L: Geographic variations in prevalence and underdiagnosis of COPD: results of the IBERPOC multicentre epidemiological study. Chest 2000, 118(4):981-989.

40. Mannino DM, Buist AS: Global burden of COPD: risk factors, prevalence, and future trends. Lancet 2007, 370(9589):765-773.

41. Black N: Why we need observational studies to evaluate the effectiveness of health care. BMJ 1996, 312(7040):1215-1218.

doi:10.1186/1471-2466-13-5

Cite this article as: Chuchalin et al:: Efficacy and safety of moxifloxacin

in acute exacerbations of chronic bronchitis: a prospective, multicenter, observational study (AVANTI). BMC Pulmonary Medicine 2013 13:5.

\section{Submit your next manuscript to BioMed Central and take full advantage of:}

- Convenient online submission

- Thorough peer review

- No space constraints or color figure charges

- Immediate publication on acceptance

- Inclusion in PubMed, CAS, Scopus and Google Scholar

- Research which is freely available for redistribution 